\title{
COMPUTATIONS OF FLOWS OVER A TURBINE BLADE
}

\author{
R.S. Amano and C. Xu
}

To meet the needs of efficient turbine blade designs, computational fluid dynamics (CFD) predictions of a complex three-dimensional (3D) flow field in turbine blade passages have been incorporated in the design process during the last decade. Owing to the numerous advantages possessed by a 3D CFD technology, many industries already use a 3D blading technique in the design process of turbomachines. In addition, blade lean and sweep have been implemented to increase the blade row efficiency. Experimental studies have shown some advantages of these features. However, most of the experimental results were combined with other features together as well, thus making it difficult to determine the effects of individual superior features. The development of CFD techniques has made it possible to do $3 \mathrm{D}$ turbulent flow analyses in a very short time. In this study, numerical studies are presented to demonstrate the sweep effects on a transonic compressor airfoil. The purpose of this study is to investigate the sweep effects without changing other compressor blade features, i.e., keeping the blade outflow angles and section shapes to be the same at design sections for all cases. Through this study, the sweep effect in a transonic compressor rotor blade was tested. The results showed that the sweeps redistribute the flow reducing the secondary flow loss, depending on the baseline. It was shown that the forward sweep reduces the tip loading in terms of the static pressure coefficient.

\section{INTRODUCTION}

Through-Flow and mean-line codes are still primary design tools for turbomachinery blade designs in industry. The Through-Flow calculation is based on a quasi-3D method to predict the flow on a streamline surface. For most of the design cases, a Through-Flow code produces satisfactory solutions when compared with experimental data. Along with the improvement of the materials, the pressure ratios of the turbines and compressors have been considerably increased.

The flow through blade-to-blade sections normally is supersonic; thus occasionally triggers a formation of a shock wave. For improving the blade design, 3D

This is an Open Access article distributed under the terms of the Creative Commons Attribution-Noncommercial License 3.0, which permits unrestricted use, distribution, and reproduction in any noncommercial medium, provided the original work is properly cited. 
blading technique can help reducing shock wave losses and secondary losses [1]. Since a Through-Flow analysis cannot give a good estimation of 3D blade flow structures, the shock wave losses and secondary flow losses are based on the testing correlations. For this reason, 3D CFD codes [2-5] have been developed to predict these flow structures. During the last decade, a 3D code has become one of the design tools used in the turbine design processes [6].

In most cases of the flow between blade rows in a turbine or compressor annulus and the stream surfaces between two annular walls, blades are designed to be twisted. Such a twist tends to induce either shed vortices or secondary flows arising from the inlet vortices. A stream surface twist can arise in an irrotational flow because of either spanwise velocity components or spanwise blade forces.

Many efforts have been made to reduce the stream surface twist and the secondary flow losses through a technique such as sweep [4], lean [5], bow [2], and twist $[6,7]$, or by making nonaxisymmetric end-wall design. However, there is little information in the open literature regarding the $3 \mathrm{D}$ features.

Most of the turbomachinery studies that have been conducted are based on simple blade geometries and single stage or row flow conditions. It seems that the aerodynamic effect of the $3 \mathrm{D}$ features is case dependent. For example, Singh et al. [2] reported that closing the blade throat near the end-walls could result in significant efficiency improvements because little fluid passed through the high loss regions. This closure tends to make the flow leaving the stator row less uniform with low axial velocities near the end-walls. The test blade also integrated other changes, such as an end-wall twist.

Walker and Denton [8] achieved an efficiency increase using almost the opposite type of blade twist near the end-wall. They explained for this enhancement is attributed to the fact that an opening of the blade throat at the end-walls could twist the flow leaving the blade more uniformly. However, they also made several simultaneous design changes on the original shape of the blade. Therefore, it is necessary to investigate the effects of a single blade feature change to better understand the 3D flow features in order to guide future blade designs.

Recently, aerodynamic sweep had been proactively adopted to improve a compressor performance and stability [9]. A sweep blade was first introduced [1] to decrease the noise level induced by shock waves. However, the sweep design of the rotor did not increase the efficiency and reduced the noise level like a sweep wing. Later studies showed that a sweep design could improve a compressor rotor efficiency. However, according to Rabe et al. [7], the pressure ratio was lower than the design intended.

Hah et al. [10] studied both backward- and forward-swept leading edge compressor blades. Their study showed that a backward swept blades could suppress the intensity of the shock loss and a forward-swept rotor-blades could be used to suppress a radial-wise secondary flow and tip entropy generation. The effects on efficiency were not great for both swept blades. The study of Hah et al. also showed that a backward swept blade suffered a loss of stall margin because 
a shock appeared near the leading edge. Conversely, the forward sweep could increase the stall margin.

The study by Xing et al. [11] showed that a stall margin of the back-sweep is about the same as that of an unswept rotor blade. These studies show that the effect of sweep on transonic compressors is not fully understood.

There are few detailed descriptions of swept blade and whether or not other design parameters were changed when sweep design was implemented. Most studies [10-12] did not report whether the test inlet and exit flow boundary conditions of the sweep blades were the same on the floes for both swept and unswept blades. Much research still needs to be conducted to better understand swept blades. In addition, it is important to maintain all the other design parameters and flow boundary conditions at the same levels to understand the single 3D features of the blade.

This paper numerically demonstrates the sweep effects of the compressor rotors, while keeping all other design parameters and inlet and exit flow conditions to be the same for all the rotor blades.

\section{NUMERICAL TECHNIQUE}

\subsection{Numerical Method}

Many 3D turbulent CFD codes have been developed based on the Reynolds averaged Navier-Stokes (RANS) equations [3-5, 13]. In most of the studies, either the time marching or the pressure-based method is typically used in computing the blade-to-blade passage flowfield. The traditional codes are limited in that each code can only predict either a compressible or incompressible flow.

More recently, the authors of [3-5] developed a time-marching scheme to predict two- and 3D turbine and compressor cascade flows and heat transfer. With this algorithm, one can calculate both compressible and incompressible flows with one numerical scheme. The basic idea of the method is to effectively use the artificial viscosity components to modify the Navier-Stokes (N-S) equations by incorporating the time-dependent terms. With these treatments, the method can avoid the eigenvalue stiffness problem for low Mach number flows by keeping the solutions within a reasonable accuracy range. In addition, it can subsequently demonstrate effective calculation capability for both low and high Mach number flows. This method has demonstrated reliable results when compared with experimental data [3-5].

The solver consists of three parts: mesh generation, N-S solver, and a turbulence closure. The optimum grid type has been discussed for many years as to which method should be used for turbine and compressor blade flow calculations. The more orthogonal the grids are, the smaller yields the numerical 


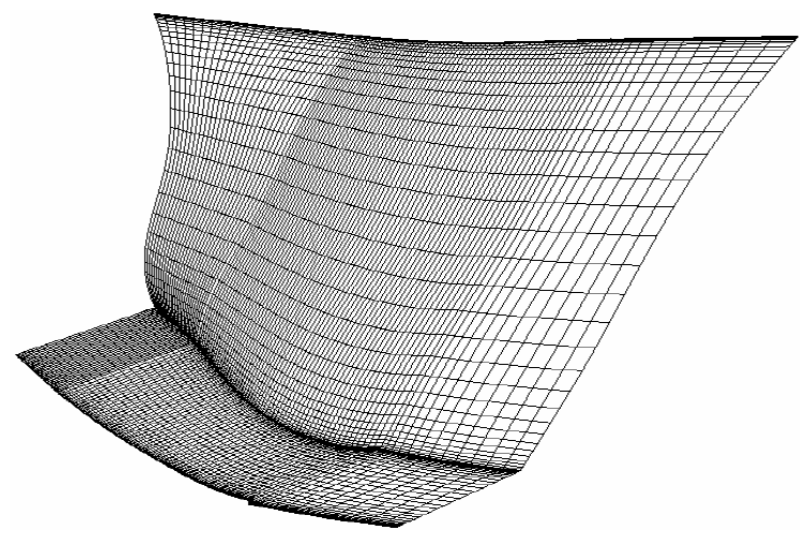

Figure 1 Mesh distribution

errors, because truncation errors are reduced with the orthogonality of the grids. However, no type of grid is ideal for blade-to-blade flow calculations. In this study, the H-type mesh, a most straightforward type, is used as shown in Fig. 1. As far as the turbulence models are concerned, there remains controversy as to which models serve as the best turbulence and transition models in compressor blade computations. In this study, the Baldwin-Lomax turbulence model [14] was employed for the flow analyses due to its favorable features for blade flow calculations $[4,5]$.

\subsection{Calculations}

In this study, unlike other sweep studies [4, 9, 15], the current baseline airfoil shapes are of modern design and have no separation at design operation point. The study reported here demonstrates the investigation technique of sweep-effects in a current state-of-the-art design. Four different compressor rotor blade rows were used in the calculations.

All calculation cases involve the same inlet and outlet conditions. The periodic boundaries were treated just as if they were interior points. The inlet total pressure, total temperature, flow angle, and outlet static pressure profiles were all taken from a multistage through-flow analysis [16]. Other flow variables were extrapolated from interior points for inlet and outlet flow. A no-slip boundary condition was applied to the blade surface. It is worth mentioning that the exit boundary conditions cannot be kept to be the same for all the calculations.

It is found that there were two different methods to hold the exit condition close to the baseline. One was to hold the mass average exit angle (the mass aver- 
age flow angle is defined by span average angle and the span direction flow angle was calculated through mass average of the flow velocity) and static pressure profiles are the same as the baseline while keeping the airfoil-section-stagger-angles to be the same. However, this method may slightly change the inlet incidences and exit total pressure. Another method was to hold the exit static and total pressures constant. This method needs to change airfoil-stagger-angle to match the exit total pressure. This is because the sweep changes the flow total pressure distributions. The first method was used for all of the calculations presented here.

The mesh size employed in the calculations was $100 \times 35 \times 41$ as shown in Fig. 1. After several mesh independent studies, it was demonstrated that the mesh size employed here is grid-independent and thus quite adequate. The calculated blade had an inner radius of $0.5 \mathrm{~m}$ and an outer radius of $0.92 \mathrm{~m}$ with a tip clearance of $1.0 \%$ of the base section chord. The blade was designed in eleven sections; the blade section shapes did not change for all the blades except the stacking orientation. For all the cases, the maximum mass flow difference is less than $0.5 \%$. Four different cases are reported in this paper: baseline gravity center stack-up blade, forward swept blade, backward swept blade, and root partial forward swept blade. All the blades have the same sections and the blade airfoil's wetted surface differences were not large. Moreover, the calculation is based on a smooth wall and the differences of the friction losses for different airfoil were small enough in all the calculations.

The sweep was usually defined in two different ways [10-12]: one uses the leading edge sweep angle, and the other uses the direct leading edge axial location. Use of the axial location is convenient during the airfoil design process [16] because the change in the axial location impacts the shifting of the sections grav-

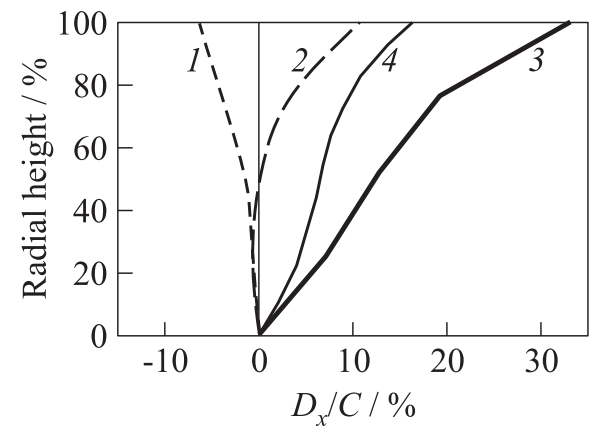

Figure 2 Sweep definition: 1 - forward; 2 - part forward; 3 - backward; and 4 - baseline

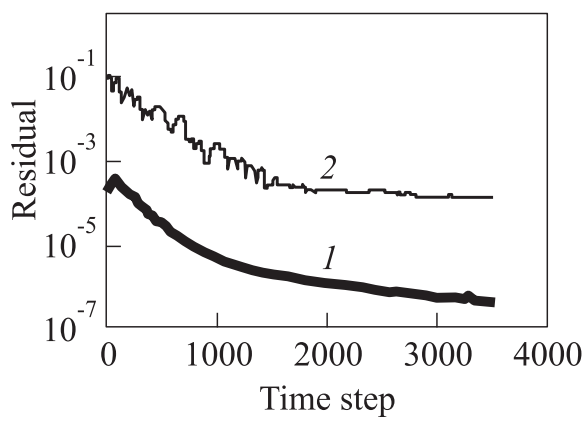

Figure 3 Convergence history: 1 RMS; and 2 - mass flow error 
ity center location, which again impacts blade structure frequency and stresses. In most of the sweep airfoil studies, the airfoil chord lengths were changed in some sections $[9,11]$ and the locations of the airfoil base section were also changed, making it difficult to see the aerodynamic sweep effects whether it is coming from the sweep or from the section changes. In this study, the base sections were fixed. This method is more reasonable during new machine design and upgrade. The only sweeps selected were those that fell within the mechanically acceptable regions. The sweeps were defined as a nondimensional parameter: the ratio of leading edge axial distance change related to the root section (DX) and the axial chord $(\mathrm{C})$. The axial changes from baseline location over the base section axial chord are shown in Fig. 2. Based on the past experiences [3-5], all calculations used the same convergent criteria during the calculation; i.e., an RMS error should be smaller than $5.0 \cdot 10^{-7}$ and the mass flow error smaller than $5.0 \cdot 10^{-4}$. A typical convergent history is shown in Fig. 3.

\section{RESULTS AND DISCUSSION}

Table 1 Total loss coefficient

\begin{tabular}{lc}
\hline Sweep type & $\begin{array}{c}\text { Total loss } \\
\text { coefficient, } \%\end{array}$ \\
\hline Baseline & 2.87 \\
Forward & 2.81 \\
Backward & 2.89 \\
Part forward & 2.85 \\
\hline
\end{tabular}

The loss coefficient is a one-dimensional coefficient, which is defined as the mass averaged relative total pressure drop over the outlet dynamic head. The mass average overall losses at the exit plane are listed in Table 1. The calculations show that the baseline and the backward sweep blades have relatively larger losses than the forward and partial forward blades. However, the loss results for sweep were not significant, which is similar to some experimental observations $[1,9,10]$. The computational results of the mass circumferential average loss coefficient profiles across the span are shown in Fig. 4, where one can see that the forward sweep reduces losses and the backward sweep increases losses in the tip region. Figure $4 b$ shows that sweeps reduce the losses at $50 \%$ span and a backward sweep has the smallest losses at the mid-span of the blade. The sweep may change the blade leading edge shock structure, thus reducing the loss in the mid-span.

The calculated mass average flow angles at the exit section show that the flow angles are almost the same, because the study kept the section parameters the same. The flow angles for the backward sweep and baseline cases are shown in Fig. 5, where one can see that the sweep blades maintain the same outflow angle as the baseline.

The isentropic Mach number at the hub section, middle span, and the tip section are shown in Fig. 6. The hub (Fig. 6a) and tip (Fig. 6c) sections have 


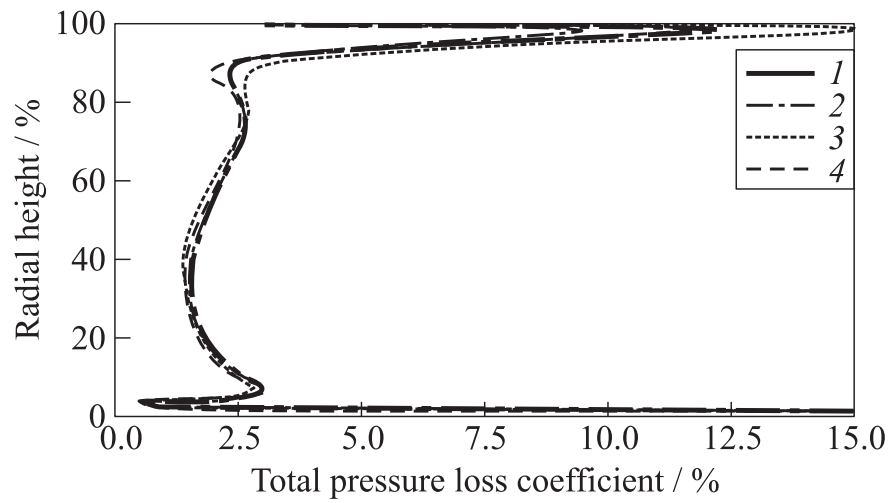

(a)

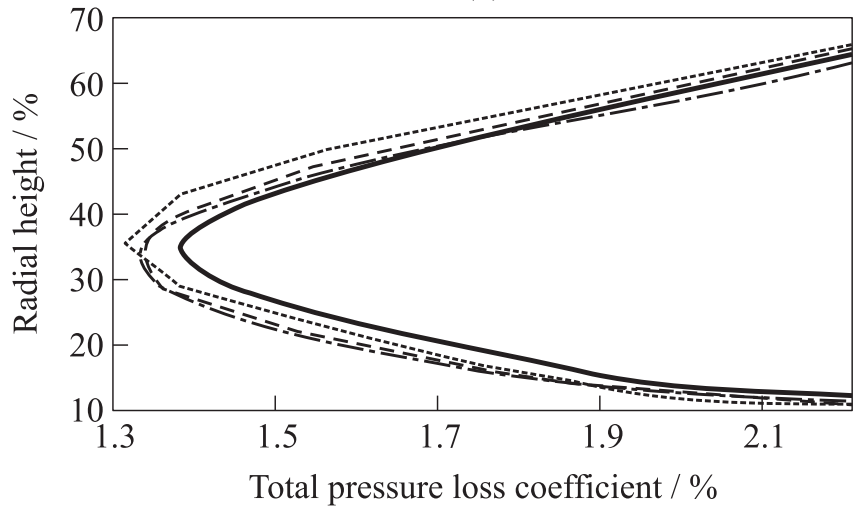

(b)

Figure 4 Total pressure loss coefficient distributions for the whole spanwise $(a)$ and near the middle span $(b)$ : 1 - baseline; 2 - forward; 3 - backward; and 4 - part forward

a larger impact than those at the middle (Fig. 6b) sections. The blade loading defines the velocity difference between the blade pressure and the suction sides for a fixed flow direction. For all the sweep cases, the leading edge loadings at the root section are larger than those of the baseline blade. Forward cases reduce the airfoil loading and backward increase the airfoil loading at the mid- and tip-sections. These results are similar to those reported in [9] but the magnitude of the loading changes are much smaller. In addition, the peak isentropic Mach number moves forward at the hub section for back sweep. This reduction in loading at the leading edge could reduce the shock waves. However, if the unswept blade did not have strong leading edge shock strength, the impact on the losses due to the reduction of the shock strength is not significant. The overall loss 


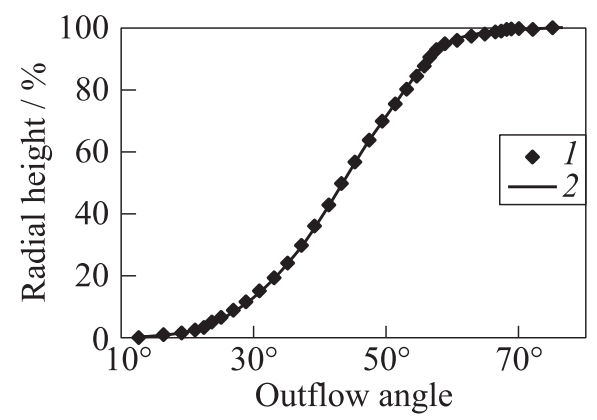

Figure 5 Mass average outflow angles: 1 baseline; and 2 - backward then is determined by the secondary flow losses. This may be the reason why some investigations $[7,10]$ reported significant loss reductions and others [12] did not in applying the sweep in airfoils. The isentropic Mach number distributions shown in Fig. $6 b$ indicate that the change of the loading was not significant in the mid-span. And the mid-span airfoil section suffers from a strong leading edge shock. Losses attributed to this feature probably overwhelm the difference in total loss coefficients.

The axial velocity contours near the suction surface are shown in

Fig. $7 a$ where the peak speed region is inclined according to the sweeps of the airfoil leading edge. The secondary flow contours for the suction and pressure side of the blade are shown in Figs. $7 b$ and $7 c$, respectively. It is shown in these figures that the forward sweep reduces the secondary flows both near the tip and the hub regions. It is also depicted that all the sweep cases reduce the secondary flows at the mid-span. The secondary flows behind the tip clearance are stronger for the back sweep than other cases. The strong secondary flow in the tip clearance region will increase the entropy generation.

The static pressure distributions near the suction surface are shown in Fig. 8. It indicates that the low-pressure region is inclined because of the change of the leading edge loading. However, the sizes of the low-pressure regions for different sweeps are distinctive. The backward sweep has the largest low-pressure region and the forward sweep has the smallest low-pressure region. The backward sweep does not present overall large losses, perhaps, because the inclination of the lowpressure region causes the inclination of the shock which reduces the losses from shock waves.

The relative Mach number contours between the blades at the hub, mid-span, and tip sections are shown in Fig. 9. All the swept blades have similar Mach number distributions at the hub section (Fig. 9a). However, the location of the peak Mach number near the suction surface moved forward for the backward sweep case, which agrees with the contours of the Isentropic Mach number plotted in Fig. 6a. At the mid-span section (Fig. 9b), Mach number distributions present a different feature after the shock waves. The backward swept blade has a relatively large region of high Mach numbers, perhaps, because the shock waves are weaker for the backward swept blade than for the other cases. Thus, it causes the shock losses at the mid-span section to be smaller for the backward swept blade which again agrees with the loss distributions shown in Fig. 4. 


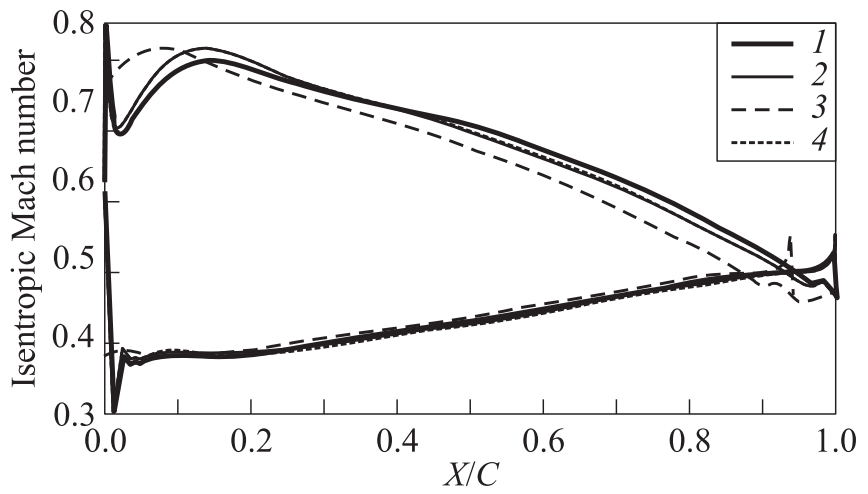

(a)

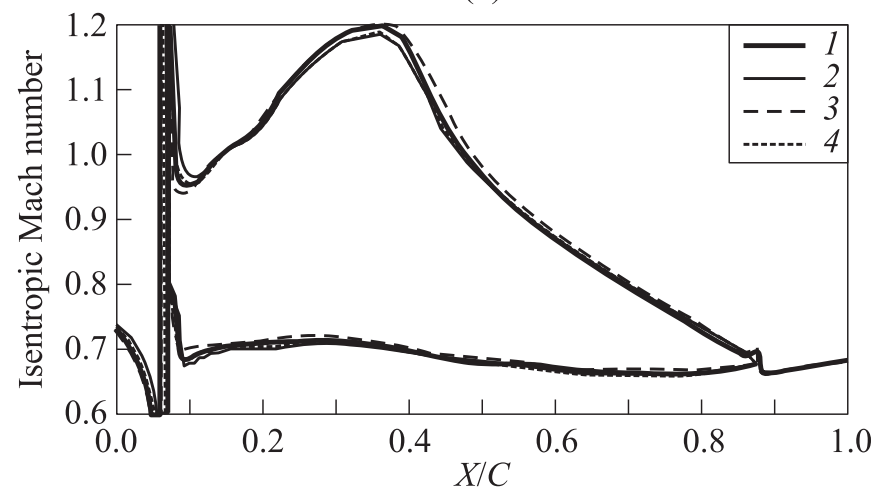

(b)

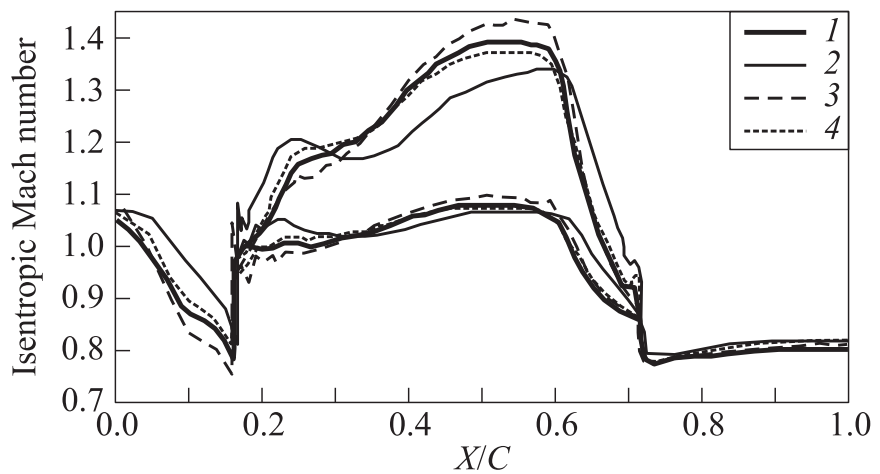

(c)

Figure 6 Isentropic Mach number distribution at hub (a), middle (b), and tip (c) sections: 1 - baseline; 2 - forward; 3 - backward; and 4 - part forward 


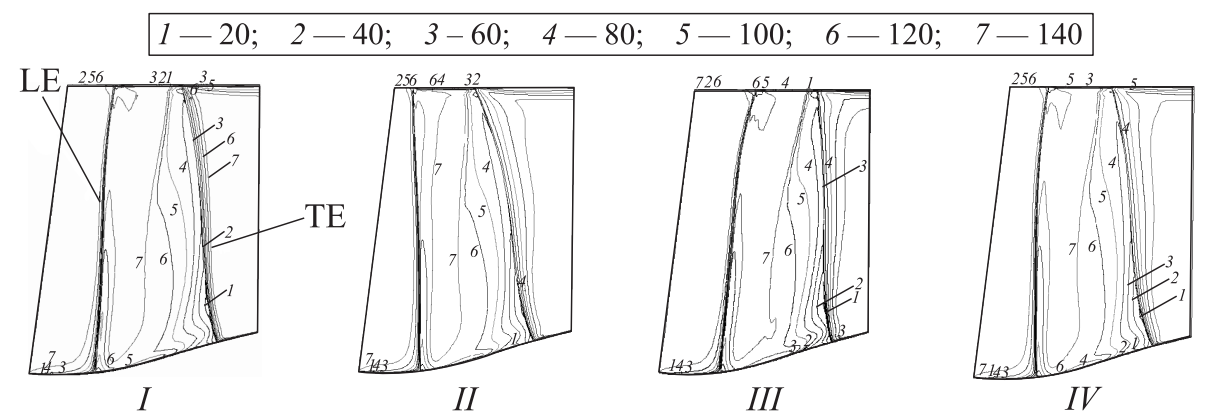

(a)

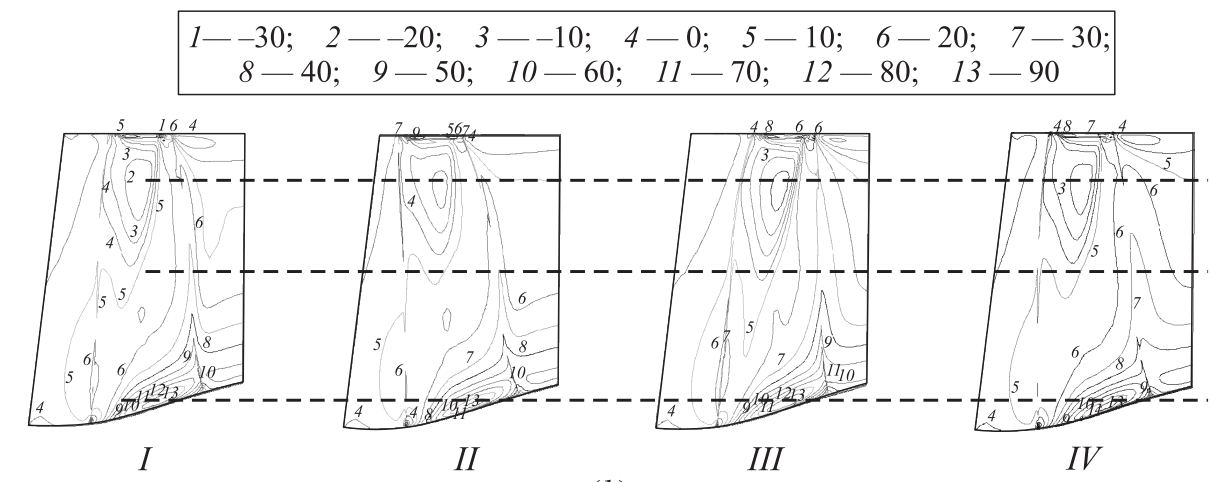

(b)

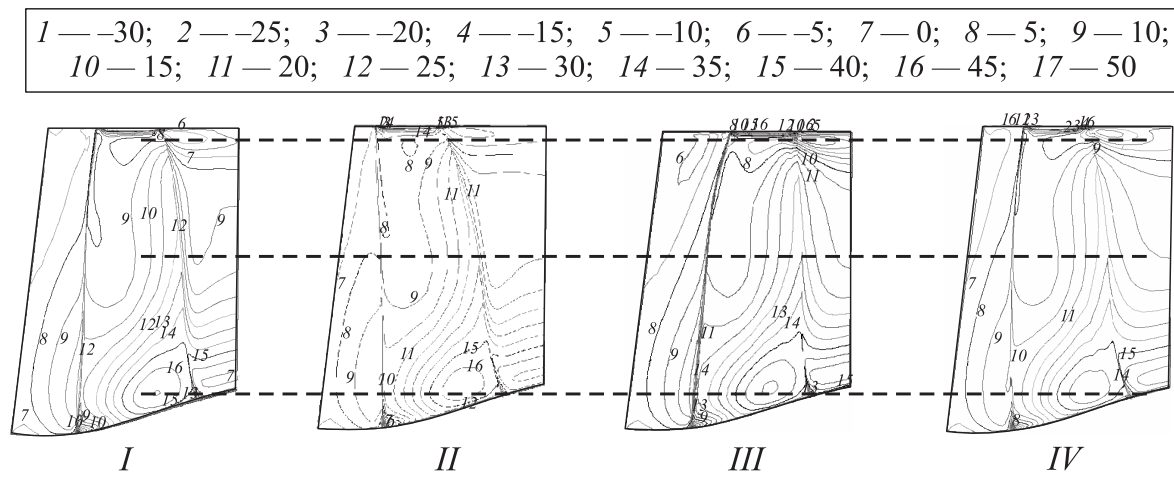

(c)

Figure 7 Axial velocity contour near the suction side $(a)$; radial secondary flow contour near the suction side $(b)$; and radial secondary flow contour near the pressure side $(c): I$ - baseline; $I I$ - forward-sweep; III - backward-sweep; and IV - part sweep 


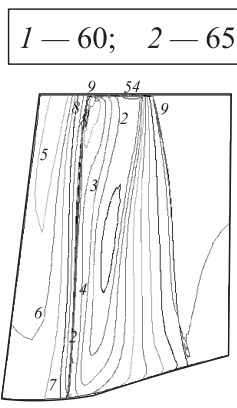

I

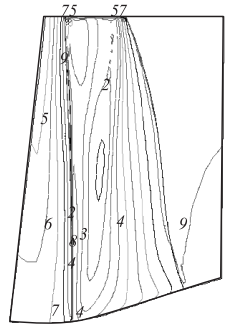

II

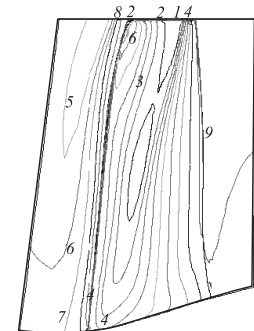

III

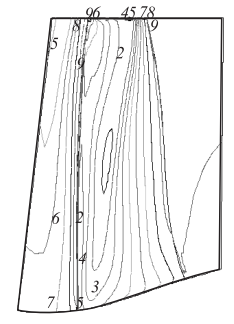

IV

Figure 8 Static pressure near the suction side: $I$ - baseline; $I I$ - forward-sweep; III — backward-sweep; and IV — part sweep

Axial velocity contours at the tip are shown in Fig. 10. The results show that the leakage flow exits the clearance gap into the passage with a negative axial velocity component. This phenomenon is caused by the effect of the combination of high tip stagger and mechanical limitations of the tip chord length. This upstream direction of leakage flow impacts the aerodynamic stability. Figure 10 also shows the lower velocity flow from tip leakage, which leaked from the pressure side of the blade, moving across the blade-to-blade channel to the next blade and mixed with the mainstream flow. This mixed flow will leak from pressure side of the airfoil to the suction side at the trailing edge. This leakage will increase the mixing losses. It is shown that the forward swept blade has much smaller reverse flow whereas the backward blade has a larger reverse flow region. A smaller region of the reversed flow will reduce the mixing losses. The flow leakage from the tip clearance increases streamwise momentum. The increase in the flow momentum can reduce the reverse flow region if a separation bubble occurs behind the tip. The reduction of the reverse flow is important for the compressor in operating near a stall condition. Therefore, at a near stall operating condition, the forward swept will be more beneficial than other designs of the blades. This is why the forward sweep can increase the operating region. The velocity contours also showed that the interaction region of the leakage and mainstream flows was narrower than the baseline design.

The mass-averaged flow distributions are shown in Fig. 11. These distributions depict that the forward swept airfoil has less mass flow at the middle span of the airfoil, whereas a backward sweep has more mass flow. The analysis showed that the mass flow close to the hub of the airfoil is almost the same. The mass flow reduction on the middle span of the forward swept airfoil moves to the tip region. An overall effect is that the mass flow distributions did not change much. Mass flow redistribution could be the cause for the change in the 


$$
\begin{array}{|r|}
\hline 1-0 ; 2-0.05 ; 3-0.1 ; 4-0.15 ; 5-0.2 ; 6-0.25 ; 7-0.3 ; 8-0.35 ; \\
9-0.4 ; 10-0.45 ; 11-0.5 ; 12-0.55 ; 13-0.6 ; 14-0.65 ; 15-0.7 ; 16-0.75 ; \\
17-0.8 ; 18-0.85 ; 19-0.9 ; 20-0.95 ; 21-1.0 ; 22-1.05 ; 23-1.1 ; 24-1.15
\end{array}
$$
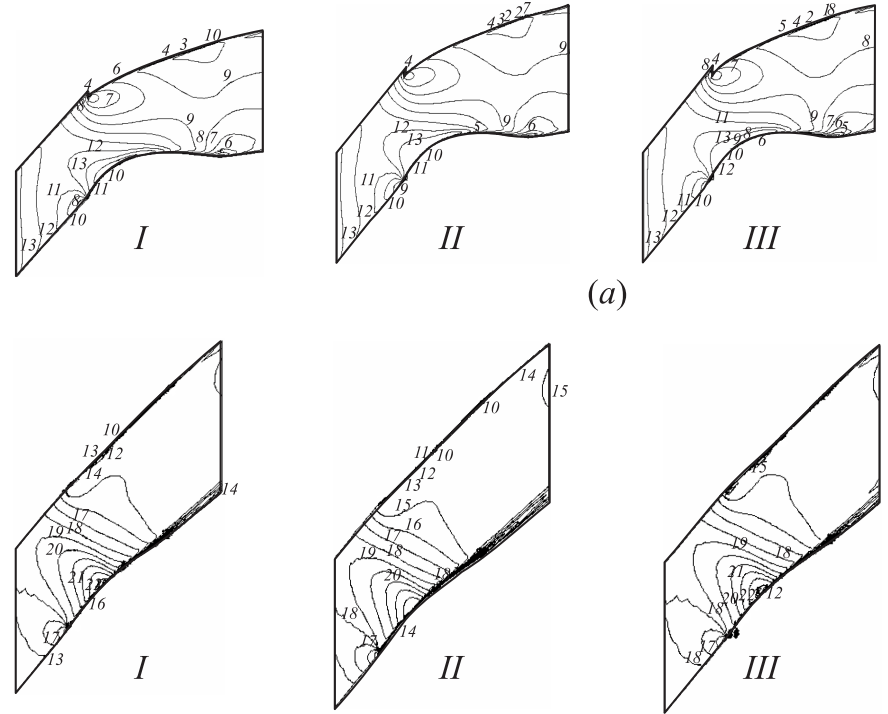

(a)
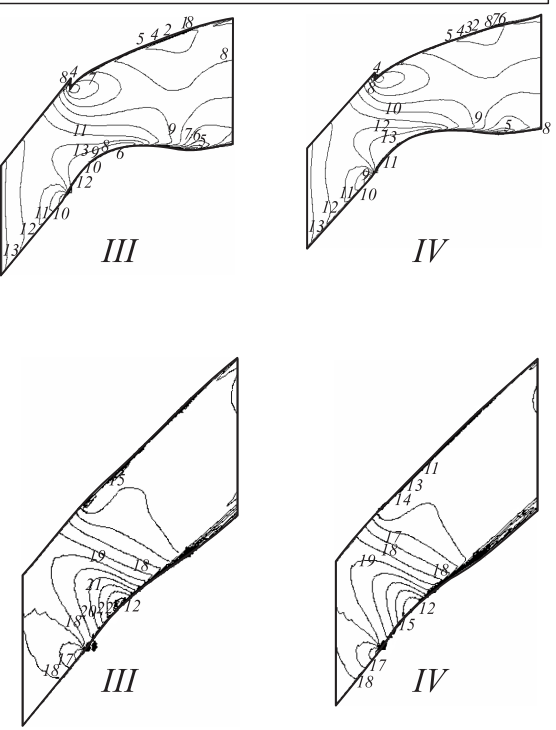

(b)

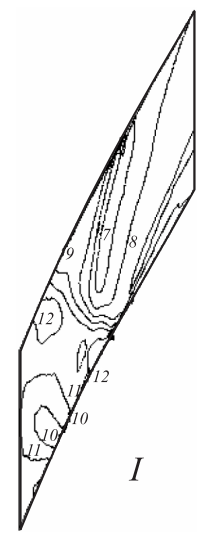

$7-0.6 ; \quad 8-0.7 ; 9-0.8$

$-0.3 ; \quad 5-0.4 ; 6-0.5$

$-0.9 ; \quad 11-1.0 ; \quad 12-1.1$
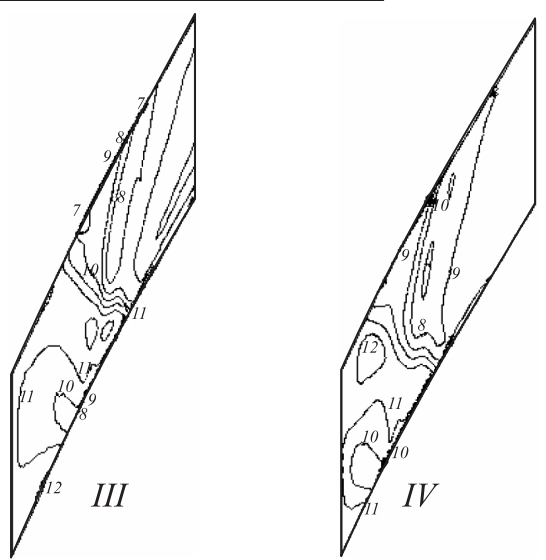

(c)

Figure 9 Relative Mach number contour near root section $(a)$; at the middle section (b); and near tip section (c): I — baseline; II — forward-sweep; III — backwardsweep; and $I V$ - part sweep 


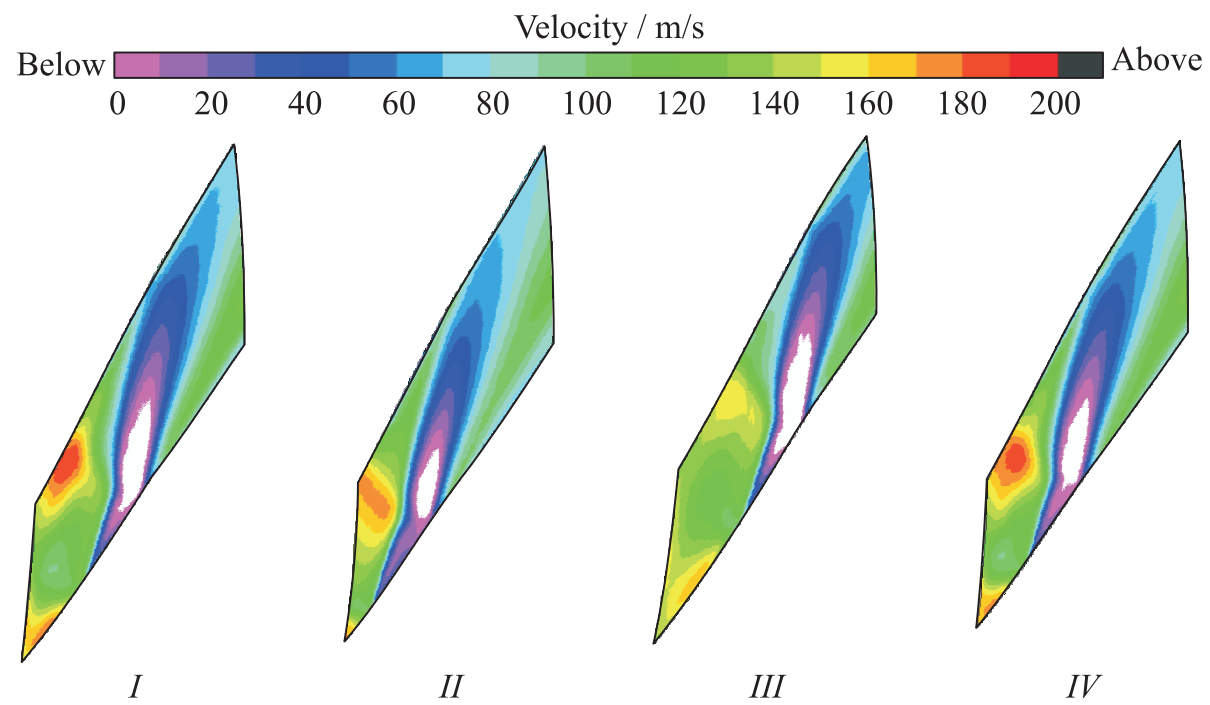

Figure 10 Axial velocity contour at the tip section: $I$ - baseline; $I I-$ forwardsweep; III - backward-sweep; and IV - part sweep. (Refer Amano and Xu, p. 621.)

tip region flow characteristics. The benefit to efficiency depends on which part is larger: e.g., the reduction of the tip mixing loss or pushing more flow to tip region to increase the losses.

The total pressure distributions at the exit station are shown in Fig. 12. The results indicate that, for the backward sweep, the high total pressure region at the tip section is larger than for the other cases. It does not show any other obvious differences in the total pressure distributions, because the magnitude of the losses for the different sweep cases are smaller.

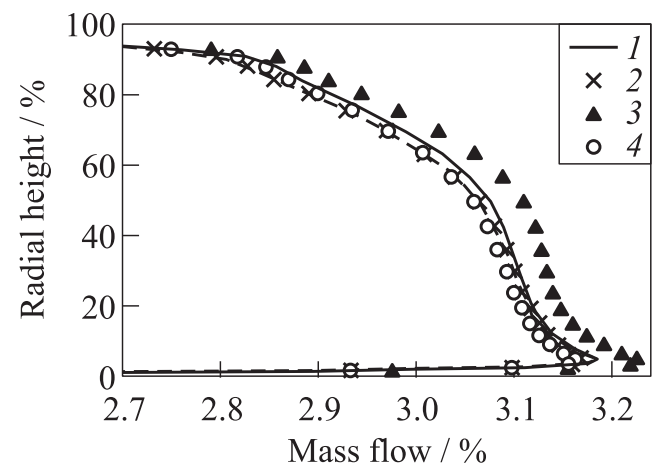

Figure 11 Mass flow distributions: 1 - baseline; 2 - forward-sweep; 3 - backward-sweep; and 4 - part sweep 


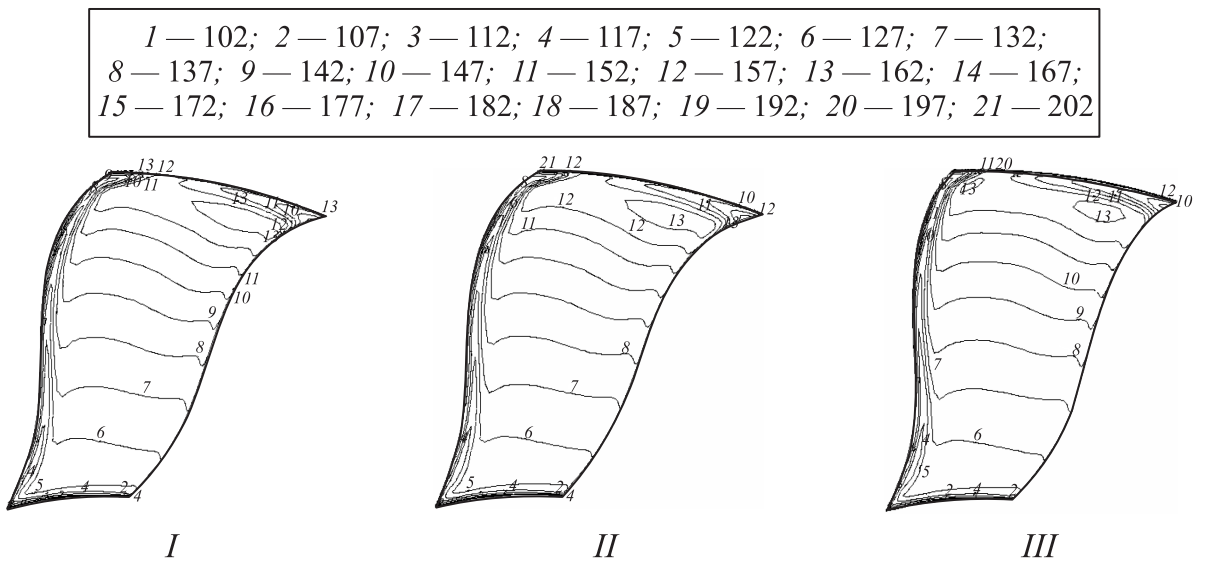

Figure 12 Total pressure distributions at exit station: $I$ - baseline; $I I$ - forwardsweep; and III — backward-sweep

\section{CONCLUDING REMARKS AND RECOMMENDATIONS}

The effects of the 3D blade sweep were predicted by using a CFD technology. The calculations showed that the sweep did not cause significant efficiency improvements for the current baseline blade. However, due to the difference of the tip flow patterns, the blade operating regions were different. The forward swept blades had the largest operating region.

The analysis showed that forward swept blades had two opposite ways to change the loss: mass flow redistribution along the span and reduction of the tip mixing loss. The overall benefit depends on which part has a larger influence. The reduction of the tip mixing loss reduces the tip blockage, which decreases the mainstream and leakage flow interaction. The reduction of the mixing loss near the tip region will benefit the downstream stator incidence.

This study revealed that the forward and backward sweeps had different impacts on the secondary flow pattern and shock wave structures. It is important for designers to understand the baseline loss patterns and then to select the suitable sweep to improve the baseline design. Without judging the baseline, it is hard to say which kind of sweeps will benefit the design best. This is the reason why some authors $[[8,9]$ have reported that a backward sweep could reduce losses and others reported [10] that a forward sweep could reduce losses. However, this study showed that the forward swept blade could benefit the operating region of the airfoil. 
In summary, this study suggests that the sweep effect is very complicated. Which sweep design should be used in the particular design needs to consider the blade aerodynamics as well as the downstream blade performance. In general, sweep can improve the design and benefit in improving the compressor aerodynamic performance.

\section{ACKNOWLEDGMENTS}

The authors are thankful for NSF support on the numerical computation under CTS 020022N.

\section{REFERENCES}

1. Bliss, D. B. 1976. Method of and apparatus for preventing leading edge shock and shock related noise in transonic and supersonic blades and like. U.S. Patent 3989406.

2. Singh, G., P. J. Walker, and B. R. Haller. 1995. Development of 3D stage viscous time marching method for optimisation of short stage heights. European Conference on Turbomachinery Proceedings. Erlangen.

3. Xu, C., and R.S. Amano. 2000. A hybrid numerical procedure for cascade flow analysis. Numer. Heat Transfer, Part B 37(2):141-64.

4. Xu, C., and R.S. Amano. 2000. An implicit scheme for cascade flow and heat transfer analysis. J. Turbomachinery 122(2):294-300.

5. Xu, C., and R. S. Amano. 2004. Computational analysis of pitch-width effects on the secondary flows of turbine blades. Comput. Mech. 34(2):111-20.

6. Xu, C., and R. S. Amano. 2001. On the development of turbine blade aerodynamic design system. ASME IGTI Turbo \& Expo. Paper No. 2001-GT-0443.

7. Rabe, D., D. Hoying, and S. Koff. 1991. Application of sweep to improve the efficiency of a transonic fan. Part II: Performance and laser test results. AIAA Paper No. 91-2544.

8. Walker, P. J., and J. D. Denton. 1998. Comparision of design intent and experimental measurements in a low aspect ratio axial flow turbine with three-dimensional blading. ASME Paper No. 98-GT-516.

9. Denton, J. D., and L. Xu. 1999. The exploitation of three-dimensional flow in turbomachinery design. Proc. Instn. Mech. Engrs. 213(Part C):125-37.

10. Hah, C., S. L. Puterbaugh, and A. R. Wadia. 1999. Control of shock structure and secondary flow field inside transonic compressor rotor through aerodynamic sweep. ASME Paper No. 99-GT-561.

11. Xing, X. Q., S. Zhou, and X. L. Zhao. 2001. Probing into the connotation of sweep aerodynamics of transonic fans and compressors. ASME Paper No. 2001-GT-0352. 
12. Wadia, A. R., P. N. Szucs, and W.W. Crall. 1997. Inner workings of aerodynamic sweep. ASME Paper No. 97-GT-401.

13. Lakshminarayana, B. 1991. An assessment of computational fluid dynamics techniques in the analysis and design of turbomachinery — The 1990 Freeman Scholar Lecture. J. Fluids Eng. 113(3):315-52.

14. Baldwin, B. S., and H. Lomax. 1978. Thin layer approximation and algebraic model for separated turbulent flows. AIAA Paper No. 78-257.

15. Ho, Y.H., and B. Lakshminarayana. 1996. Computational modeling of threedimensional endwall flow through a turbine rotor cascade with strong secondary flows. J. Turbomachinery 118(2):250-61.

16. Xu, C., and R.S. Amano. 2002. Turbomachinery blade aerodynamic design and optimization. Paper No. GT-2002-30541. 